\title{
Aproximación al pasado, presente y futuro de la industria azabachera, un patrimonio cultural, material e inmaterial, en vías de extinción
}

\author{
Andrea Menéndez Menéndez ${ }^{a}$
}

${ }^{a}$ AMM Arqueología y Gestión del Patrimonio, andreamdz@gmail.com

\begin{abstract}
Resumen
El uso del azabache, y otros materiales afines, como elemento de adorno personal y amuleto se remonta a las primeras sociedades prehistóricas. Esta materia prima es relativamente escasa en la naturaleza, pero desde etapas muy tempranas es un objeto codiciado y buscado, tanto desde el punto de ornamental como simbólico, dentro y fuera de la península ibérica. En este trabajo haremos un breve recorrido sobre este patrimonio, tanto material como inmaterial, en vías de extinción, con importantes conexiones históricas y culturales en diversas partes del mundo, tomando como objeto central el caso de la península ibérica. Arqueológicamente se ha podido documentar la presencia de esta materia prima en diversos contextos geográficos y cronológicos, fundamentalmente formando parte de ricos ajuares funerarios. Expondremos de forma sucinta los paralelismos históricos existentes en diversos centros productores en torno a las labores extractivas mineras, la talla, uso y significado. Por último afrontaremos la problemática en cuanto a su situación actual y el incierto futuro de este patrimonio cultural, en buena medida inmaterial, que aglutina historias, tradiciones y creencias que transcienden más allá de los propios centros productores.
\end{abstract}

Palabras clave: azabache, pseudoazabache, joyería, etnografia, amuleto, artesania, artesanos, arqueología, minería.

\begin{abstract}
The use of jet, and jet-like, as an element of personal adornment and amulet dates back to the earliest prehistoric societies. This raw material is relatively scarce in nature, but from very early stages, it is a coveted and sought after object, both from ornamental and symbolic point of view, inside and outside the Iberian Peninsula. In this paper we will take a brief tour of this heritage, both tangible and intangible, on the way to extinction, with important historical and cultural connections in various parts of the world, taking as a central object the case of the Iberian Peninsula. Archaeologically, it has been possible to document the presence of this raw material in various geographical and chronological contexts, fundamentally forming part of rich burials offerings. We will briefly expose the parallels existing in various historical production centers around mining extractive work, jet carving and its use. Finally, we will focus on its current situation and the uncertain future of this largely, intangible, cultural heritage, which brings together stories, traditions and beliefs that transcend beyond of the producing centers.
\end{abstract}

Keyword s: jet, jet-like, jewelry, ethnography, amulet, crafts, artisans, archeology, mining. 


\section{Introducción}

El azabache, término de origen árabe usado desde la Edad Media en la península ibérica y, posteriormente, por herencia cultural y lingüística, en otros países de habla hispana, es una materia prima singular que ha sido utilizada por el hombre como elemento de adorno personal y amuleto, desde la prehistoria hasta la actualidad, en diversas partes del mundo. Son diversos los históricos centros productores de azabache, y otros materiales afines, como el lignito y otros carbones, que comparten formas de explotación, trabajo, uso y significado desde etapas muy tempranas, en lugares muy dispares.

El material tiene sus propias características y denominación según su origen geográfico, pero es en definitiva un material orgánico, carbonoso susceptible de poder ser tallado. En concreto el de Oles, en Les Mariñes (Villaviciosa, Asturias), históricamente conocido por su calidad y especialmente por su relación con el Camino de Santiago es definido geológicamente como un carbón húmico, perhidrogenado, formado por material leñoso fosilizado en el Jurásico Superior. Se diferenciaría del lignito, en cuyo grupo se incluía anteriormente, por el contenido de hidrógeno, que indicaría la impregnación del material, en sus estadios formativos, por hidrocarburos petrolíferos, lo que le confiere sus peculiares características y estabilidad para ser usado en joyería (Suárez et al., 2006). Ha sido tradicionalmente equiparado por su calidad y características al también afamado azabache inglés de la zona de Whitby (Yorkshire), en este caso del Paleolítico Inferior.

Asimismo, a nivel peninsular es históricamente conocida la explotación de los recursos de azabache de la zona de Batalha y Peniche, en el entorno de Lisboa, también con origen jurásico (Costa, 2008); y en la zona de Teruel, de origen cretácico, y por lo tanto con otras características, pero también ampliamente explotado (Ona, 1988). En el resto de la península ibérica, incluidos los propios centros productores de azabache ya citados, se documentan múltiples depósitos de material cretácico o de lignito en sentido amplio, y otros materiales afines, que también han sido muy utilizados, con fines similares, desde fechas muy tempranas (Álvarez-Fernández, 1999; Menéndez, 2019b).

En estas líneas haremos un breve recorrido en torno a la explotación, uso y trabajo de esta materia prima estableciendo de forma muy sucinta, dada la extensión disponible, un análisis comparativo desde diversos puntos de vista, con otros centros productores con los que existen interesantes conexiones históricas y culturales poniendo de manifiesto la necesaria puesta en valor de este legado patrimonial, en vías de extinción a nivel peninsular e internacional

\section{El uso histórico del azabache, y otros materiales afines, como elemento ornamental y amuleto}

A grandes rasgos podemos decir que la búsqueda de esta materia prima, junto con otras afines, comenzó de forma temprana, pudiendo remontarnos al Paleolítico Superior para el caso europeo, y concretamente en el caso peninsular, con diversos materiales localizados en Asturias, como algunas cuentas y colgantes. Desde el inicio de su uso, la carga simbólica es importante y muestra de ello es su especial vinculación con el mundo de la muerte siendo habitual su temprana localización formando parte, fundamentalmente, de ajuares funerarios en forma de cuentas de collar o elementos más singulares, aunque también de pequeño tamaño, como colgantes con representaciones femeninas esquemáticas, representaciones de animales etc., como los localizados en otros contextos europeos (Álvarez-Fernández, 1999; 2003; Corchón, 2007-2008). En los primeros tiempos este simbolismo es difícil de determinar, aunque paulatinamente quedará patente el uso de la materia prima con una importante carga profiláctica, que se ligará en diversas épocas con morfologías o connotaciones de carácter apotropaico, que fortalecen o incrementan esta función protectora en diversas vertientes.

Los artesanos buscaban, en definitiva, un material, con unas connotaciones determinadas, que no han llegado hasta nosotros, relacionadas, quizás, con su color, tacto, origen, textura etc. que a simple vista podía resultar similar o susceptible de ser tallado. Por esta razón, en muchas ocasiones utilizaban materiales afines, pero de diferente calidad o naturaleza, como diversos carbones, o esquistos, que a veces han sido combinados entre sí en una misma pieza o conjunto ornamental. Este tipo de materias primas han sido englobadas por diversos autores en los términos "jet-like" o "pesudogagat", u otros similares, en contextos como Inglaterra, Alemania o el entorno del mar Negro y el Cáucaso, donde, al contrario que en la península ibérica, su estudio específico, desde un punto de vista arqueológico y analítico, 
comenzó en algunos casos de forma temprana, ya en la primera mitad del siglo XX. Son espacios con los que podemos establecer importantes conexiones desde un punto de vista tipológico y cultural. Para profundizar en este punto, de enorme complejidad, nos remitimos al estudio específico publicado recientemente en el que se aborda extensamente, y en profundidad este y otros aspectos del azabache desde una perspectiva arqueológica (Menéndez, 2019b).

Ya en el ámbito heleno aparece mencionado en tratados y lapidarios, que ya recogían algunas tradiciones anteriores en cuanto a las propiedades mágico-medicinales aplicadas a esta y otras materias primas. Plinio el Viejo recopila posteriormente buena parte de estos textos en el siglo I d.C. en su Historia Naturalis. El material es denominado "lapis gagates", ubicando su origen a orillas del río Gagas, en Asia Menor, zona identificada con la actual Turquía, donde efectivamente en la actualidad aún existe una importante tradición y legado en torno a la explotación y uso de esta materia prima (Menéndez, 2003a). Esta denominación recogida por Plinio, que es repetida posteriormente por múltiples autores hasta la Edad Moderna, con algunas variaciones y añadidos, posiblemente englobase características de diferentes materiales, con similitudes macroscópicas, con los que las diferencias eran confusas. Esta problemática ya ha sido analizada y ampliamente abordada por otros autores, por lo que no nos extenderemos más en este punto, ya que no es el objeto de este trabajo. Simplemente como dato de interés, será ya en el siglo III d.C. cuando los textos nos hablen de su abundante presencia en Britania aunque, por el momento, debemos esperar hasta el siglo XI a que se cite documentalmente su presencia en la península ibérica (Allason-Jones, 1996; Hagen, 1937; Hernández-Vaquero, 2015; Menéndez, 2019b).

Algunas de las curiosas afirmaciones y connotaciones aplicadas al azabache, dentro de los parámetros mágicomedicinales de la época, recogidas por Plinio eran por ejemplo que ahuyentaba a las serpientes; daba a conocer la epilepsia y la virginidad; recreaba las sofocaciones o ahogamientos de la madre; era usada en axinomancia como herramienta de adivinación o que cocida en vino curaba los dientes y mezclada con cera los lamparones (Menéndez, 2003a).

En la Edad Moderna se pone en marcha un importante comercio de piedras preciosas con aplicaciones medicinales basadas en la lapido-terapia, donde una vez más el azabache está presenté. Por ejemplo en el Hortus Sanitatis, editado por primera vez en Alemania a finales del siglo XV, del azabache se repiten premisas de las ya citadas en los textos clásicos y otros como que "ahuyenta a los demonios" o "ayuda en el dolor de estómago y en el parto". La obra contiene el dibujo de un joven enseñando piezas de azabache sobre una mesa. En la misma línea y como curiosidad y continuidad de las creencias en torno al poder medicinal, curativo o mágico de la materia prima, en un pleito del siglo $\mathrm{XV}$, en Oviedo (Asturias), recogido por diversos autores, contra un boticario que suministró un bebedizo de vino blanco y polvo de azabache a un canónigo enfermo, que terminó falleciendo; el boticario alegaba que "avía oydo e ge lo avía mostrado en secreto un grand físyco espirimentado". En otros textos alaban las virtudes del azabache usado, por ejemplo, como colirio (Menéndez, 2003b).

De la denominación clásica ya citada derivan los nombres por el que esta materia prima es conocida actualmente en diversos países como Alemania, las Islas Británicas, Francia, Rusia, Italia etc: jet, jais, gagat, gagate, giaietto.... En la península ibérica es conocido como azabache, y otras palabras derivadas, acibeche, acebache, atzabeja..., o azeviche en el caso portugués, términos de origen árabe, como ya hemos apuntado (Osma, 1999). En zonas como el Cáucaso es conocido como gicher, que significa "noche" y su uso como elemento protector es similar (Petrov, 1982).

El hecho de compartir rasgos con el ámbar, material usado también habitualmente como amuleto protector en épocas y contextos diversos, como su tacto cálido y sus cualidades triboeléctricas, puede ser la causa de que en ocasiones también se le denominase ámbar negro desde época clásica. Esta misma definición se mantiene aún hoy en día en centros productores como Turquía o Georgia, junto con otros nombres locales como "piedra Oltu" en el caso turco, lugar donde se localizan las vetas de material en la región de Erzurum, donde también son abundantes los estudios en torno al material desde diversos puntos de vista.

El material se utilizará en los contextos geográficos ya citados, y muchos otros, en diferente medida en época protohistórica. En el caso peninsular es importante su presencia en enterramientos relacionados con el mundo megalítico fundamentalmente transformado en cuentas de collar a veces en lugares muy alejados de yacimientos de materia prima, por lo que son consideras piezas exóticas con alto valor simbólico (Fig.1:1). En la Edad del Bronce son 
de especial relevancia algunos collares articulados en forma de creciente lunar, también una iconografía importante carga simbólica y protectora, localizados en las Islas Británicas. Seguirá usándose en la Edad del Hierro, pero sin duda la máxima explosión del uso de estas materias primas se dará en diversos centros productores ya a partir del siglo III d.C. Quizás ligado a la moda, pero también a importantes cambios sociales que suceden en estas fechas, existe una explosión del uso de materiales negros en joyería en todo el Imperio Romano, donde el azabache cobra relevancia como material de lujo, exclusivo y simbólico, con una importante carga profiláctica y apotropaica vinculada especialmente al mundo infantil y femenino, aunque no exclusivamente. Tipológicamente existen múltiples piezas cuyos paralelos pueden rastrearse por todo el Imperio y más allá de los propios limes, fruto de intercambios comerciales, movimientos de tropas y traslados de población, que afecta tanto a la materia prima en bruto, como a piezas elaboradas. Para las piezas localizadas en Iberia, podemos hablar tanto de producciones importadas, como de producciones locales, algunas de ellas con importantes influencias en Oriente Medio y Próximo. Muchas de las piezas documentadas en azabache son recreaciones de otras piezas de tradición clásica, como brazaletes, collares, pulseras, anillos etc. realizadas en materiales nobles como el oro o la plata. También es habitual la combinación de azabache con otras materias, como las ya citadas, o el ámbar, creando joyas con interesantes juegos cromáticos de enorme contraste y belleza (Figs. 1:3, 4, 5, 6, 7) (Menéndez, 2019b).

El desconocimiento generalizado en torno a esta materia prima a nivel peninsular en muchos aspectos, hace que sea complicado rastrear a veces estos materiales, que a menudo están clasificados y expuestos en museos como otras materias primas. Como ejemplo de este desconocimiento, una noticia en la plataforma de noticias científicas SINC del año 2010, en torno a una posible "denominación de origen" para el azabache asturiano, firmada por uno de los responsables del que fue el Grupo de Investigación "Azabache y leño fósil" de la Universidad de Oviedo se ilustra, hasta el día de hoy, con unos supuestos brazaletes de azabache, que son en realidad unas características piezas de bronce de la cultura de Hallstatt (Bronce Final-I Edad del Hierro) de Europa Central. La misma imagen se usa en la misma línea en diversas plataformas (Menéndez, e.p.).

Junto a magnificas joyas, que pueden tener una doble vertiente, tanto ornamental como simbólica, como anillos o brazaletes, a los que se les atribuye poderes mágicos, tanto por la materia como por la forma, se han documentado piezas con un mayor peso como amuleto, como es el caso de algunas cuentas de collar, ampliamente distribuidas en la península en época tardorromana y visigoda, con profusa decoración de círculo y punto, iconografía ampliamente utilizada en diversas culturas y materias primas, ligada al ojo, o al sol, como elementos protectores, con paralelos que pueden rastrearse en azabache, y materiales afines, en el entorno del mar Negro, ya en la Edad del Hierro y posteriormente en época romana (Fig. 1:2) (Menéndez, 2019b). También se han documentado algunos amuletos, como las bullae, portadas por los niños y habitualmente realizadas en otros materiales; o piezas más singulares, como los pequeños bustos antropomorfos que parecen representar luchadores, púgiles o personajes con gestos grotescos, con una importante carga apotropaica, que han sido localizados en contextos diversos, principalmente ligados a enterramientos femeninos o infantiles (Fig. 1:8). Lo mismo ocurre con otras piezas muy características, usadas con el mismo fin protector, como son, entre otros, algunos medallones con la representación de Medusa localizados en Inglaterra o Alemania (Menéndez, 2019b).

A partir de la Edad Media sin duda el uso del azabache peninsular, y fundamentalmente el azabache asturiano, estará ligado al desarrollo del Camino de Santiago. Desde fechas tempranas, el gremio de azabacheros de Santiago de Compostela determinó el uso exclusivo de la materia prima asturiana en sus ordenanzas, considerándola de mejor calidad frente otras, tratando de asegurarse así un rico monopolio, intentando frenar la talla de material de calidad y procedencia diversa que podía ser adquirida por los peregrinos a lo largo del camino, amenazando las ganancias del monopolio de la cofradía. Ya en el siglo XV, la cofradía denuncia estas prácticas y en unas ordenanzas del siglo XVI se insta a que no entre en la ciudad otro material que no sea el de Asturias, afirmando que "en Portugal y Monte Alban ha mucha acebache falssa" (Osma, 1999). Sin embargo y pese a las premisas adoptadas por el gremio azabachero santiagués, defendiendo su monopolio, se ha documentado la exportación de grandes cantidades, tanto de material en bruto, como ya elaborado, procedente de la zona de Montalbán (Teruel), así como la presencia allí de mercaderes y artesanos gallegos y asturianos, entre otros, ya en el siglo XV (Martínez, 2016). Lo mismo ocurriría en el caso 
portugués y al contrario de lo que pudiese pensarse, a tenor de lo expresado en las ordenanzas del gremio santiagués, en Asturias, por supuesto, también existía, y existe, material de mala calidad.

Relacionados con esta faceta artística compostelana se conservan en museos y colecciones públicas y privadas de todo el mundo piezas realmente excepcionales, como pequeños conjuntos escultóricos y otras piezas e temática religiosa, como cruces procesionales, piezas relacionadas con la peregrinación, rosarios, collares de abadesa y un largo etcétera, que fueron ampliamente estudiadas por diversos autores desde fechas tempranas. Arqueológicamente se han podido documentar pequeños recuerdos de peregrinación, como veneras y otras piezas que se colgaban o cosían en la ropa o los sombreros de peregrino, como la pieza fragmentada, en fase de estudio, localizada por nosotros en una necrópolis extremeña (Fig. 1:9). También se han documentado focos artesanos de gran interés, como el taller bajomedieval excavado en Villaviciosa (Asturias) en los años 90 (Menéndez, 2003a).

En el caso portugués, menos estudiado que el español, también pueden localizarse piezas de enorme interés, y con particularidades geográficas, de cronologías diversas, en sus museos, que denotan una explotación temprana de sus recursos (Menéndez, 2019b). Asimismo también está atestiguada documentalmente una industria minera y artesana al menos desde el siglo XVI, hasta ya su desaparición a finales del siglo XIX (Travaços, 2011).

Con usos similares al caso español es interesante citar, por ejemplo, el caso alemán, donde se documenta la presencia también de una minería a principios del siglo XV y en el XVI y documentación ligada a un gremio de azabacheros, cuya decadencia comenzó a mediados del XVII, frente a la supremacía inglesa y española (Hagen,1937). O el caso inglés, donde el azabache en estas fechas tuvo un uso vinculado también al mundo eclesiástico o protector, con la producción, aunque menor, de pequeñas cruces o rosarios fundamentalmente. $\mathrm{O}$ el caso francés, donde también hubo una importante industria ligada a esta materia prima en la zona del Languedoc, con material de origen cretácico, particularmente conocida por sus rosarios, que declinó a finales del siglo XIX, con la expansión del denominado "azabache francés", un popular tipo de vidrio negro (Muller, 1987).

Pero también se hacían piezas más del gusto popular, joyas más sencillas como collares, botones, pendientes, pasadores y todo tipo de dijes, que han sido recuperados en yacimientos arqueológicos diversos. Sin duda, la pieza popular por excelencia, ligada a esta materia prima como elemento protector en la península ibérica ha sido la higa de azabache. Esta iconografía gestual de la mano fue muy utilizada en el mundo clásico, y fechas anteriores, en Oriente Medio y Próximo, entre otras cosas, asociada a la defensa contra el denominado "mal de ojo" o "fascinación" realizada en todo tipo de soportes y materiales y también era habitual reproducir este gesto, con el pulgar entre el dedo índice y el corazón, como método de defensa. Fue introducida en la península de la mano de los fenicios, y muy utilizada en Época Romana, donde también se vincula con la representación de la vulva femenina, por lo que era habitual su representación en diversos tipos de amuletos fálicos. En el mundo musulmán el "mal de ojo" también tenía un peso importante usando en el norte de áfrica un amuleto protector en forma de mano abierta, la hamsa que también se introdujo en la península ibérica. Las higas de azabache más antiguas hasta la fecha han sido datadas por el momento en el siglo XIII. Con el tiempo se convierten en imprescindibles amuletos, muy arraigados en la sociedad, relacionados con la protección contra el "aojamiento", muy vinculado al mundo infantil, uniendo el carácter protector de la materia prima, con el ofensivo de la forma gestual de la mano aunando en una misma pieza elementos protectores pasivos y activos. Este elemento es utilizado por todas las clases sociales en múltiples formatos y tamaños, costumbre que ha llegado a nuestros días, con la creencia de que el amuleto atraía la mirada del "aojador" protegiendo así al portador (Fig. 1:10). Las primeras, más sencillas y de pequeño tamaño, fueron evolucionando a partir del siglo XVI hacia piezas más estilizadas que enmascaraban su forma llegando a las grandes piezas utilizadas en el siglo XVII, cubiertas de simbología religiosa o compostelana, que pretendían ocultar la gestualidad pagana, ya que las autoridades condenaban su uso, a menudo vinculando estos objetos con la influencia morisca. Sin embargo también era muy utilizada por miembros de los estamentos religiosos. Prueba de su arraigo social es la representación constante de estos elementos en los retratos de infantes del siglo XVII. La mortalidad infantil era muy alta y solían portar cinturones de los que colgaban decenas de amuletos de todo tipo, y otros eran cosidos en la ropa. Paulatinamente la higa recupera su forma primitiva en forma de pequeños dijes a partir del siglo XVIII (Osma, 1999; Franco, 1986 y siguientes; Menéndez, 2003a). 
Con la decadencia del camino, además del comercio de piezas populares a nivel peninsular, se fomentan nuevas vías comerciales y comienza ya en el siglo XVI un comercio con América que se mantiene con altibajos hasta mediados del siglo XX, donde piezas como la higa se convierten en un elemento ampliamente utilizado, pasando a formar parte de la cultura popular de los países del nuevo mundo. En algunas zonas se recrearán esta, y otras formas, con sus propios materiales autóctonos, a los que también denominaran azabache por sus similitudes macroscópicas, como es el caso del llamado azabache venezolano (Franco, 1991; Monte, 2004). Aunque no existe demasiada información al respecto, esta materia prima ya se trabajaba en época precolombina (González, 1989). La simbología exportada a América, como la forma de la higa, los rosarios y otras piezas, pueden ser todavía rastreadas hoy en día, realizadas en estas materias primas locales y son incluso importadas actualmente a nuestro país manteniendo el mismo uso y significado profiláctico y apotropaico, muy vinculado con el "mal de ojo", en un nuevo giro a las conexiones culturales compartidas creando interesantes híbridos culturales, con sus propias particularidades (Menéndez y Tuero, e.p.).

La última gran explosión de la industria azabachera, tanto en la península, como en Inglaterra, se produce de la mano de la moda victoriana inglesa vinculada al luto, a finales del siglo XIX, que se mantuvo con altibajos hasta principios del siglo XX, lo que supuso un importante desarrollo de la minería española, con la exportación de cientos de toneladas de material en pocos años (Monte, 1986).

Ya desde el siglo XIX la proliferación de materiales más baratos, como las resinas artificiales o naturales que se comenzaron a utilizar, ante la alta demanda de materiales de color negro, o el ya citado "azabache francés" supusieron la caída definitiva de una industria, cuya dificultosa extracción dejó de ser rentable económicamente frente a materiales de bajo coste más fáciles de conseguir.

En otros centros como Turquía el material ha sido explotado y trabajado al menos en los tiempos más recientes, desde el siglo XVIII produciendo también materiales del gusto popular muy apreciados aún en la actualidad (Parlak, 2001).

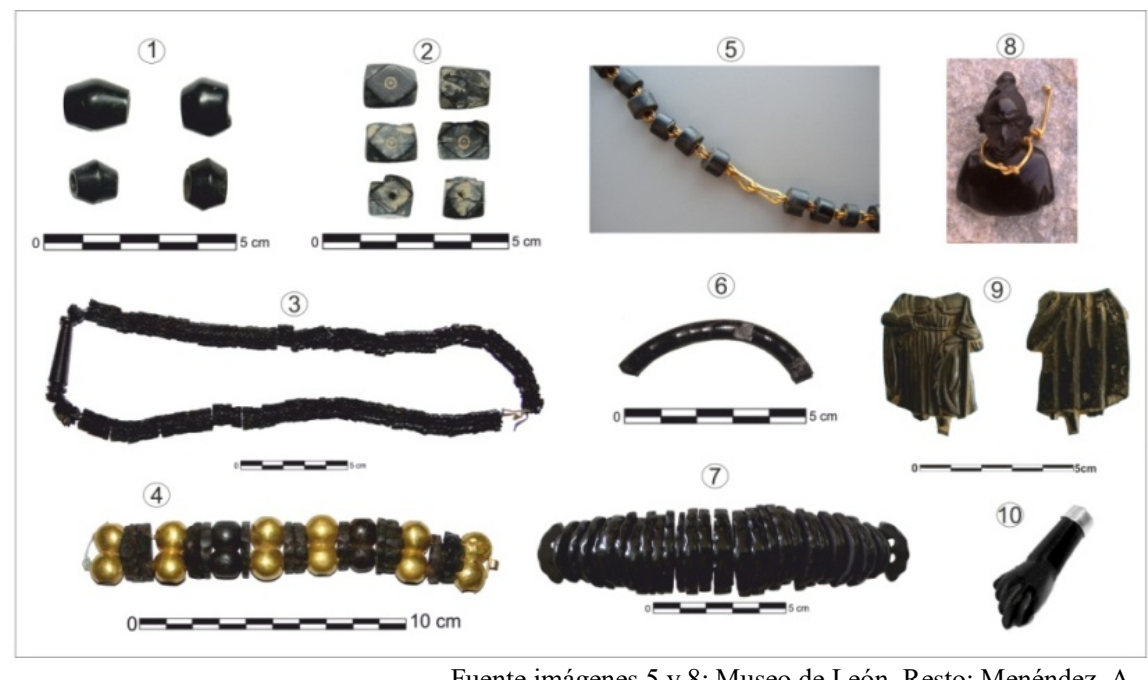

Fuente imágenes 5 y 8: Museo de León. Resto: Menéndez, A

Fig. 1. Algunas piezas de azabache recuperadas en yacimientos arqueológicos de la península ibérica (1-9); y un amuleto todavía usado en la actualidad (10): 1). Cuentas del calcolítico. Museo Arqueológico de Cáceres. 2). Cuentas tardorromanas.

Museo Arqueológico de Cáceres. 3, 4 y 6). Collar; brazalete articulado combinado con oro y brazalete rígido de época romana, clasificados y publicados como otras materias primas. Museo Nacional de Arte Romano de Mérida. 5 y 8 ). Detalle de collar de azabache y oro y amuleto antropomorfo de época romana. Museo de León. 7). Brazalete articulado de época romana. Museu Nacional de Lisboa. 9). Figura de Santiago peregrino de época moderna. Museo Arqueológico de Badajoz. 10. Higa de azabache actual

\section{Explotación histórica de la materia prima. Un legado minero y artesano internacional}

En España en torno al azabache surgieron ya intereses en el siglo XIX ligados a estudios geológicos y, fundamentalmente, a su relación con el Camino de Santiago, desde un punto de vista artístico y documental, con 
importantes e imprescindibles contribuciones de autores ya citados, y muchos otros, también de carácter internacional, que pusieron el foco en diversas colecciones de azabaches compostelanos, tanto públicas, como privadas y especialmente en los artistas gallegos (Franco, 1986). Este interés continuó hasta finales del siglo XX y en fechas posteriores, con publicaciones de diversa índole, con mención especial para los trabajos de Ángela Franco Mata. Pero desde nuestra perspectiva de investigación son especialmente interesantes los estudios realizados desde un punto de vista minero-artesanal vinculados a los focos productores de materia prima, donde el conocimiento era más sesgado y limitado. De los focos productores mineros históricamente conocidos de la Península: Asturias, Portugal y Teruel, el caso mejor estudiado es sin duda el de Asturias, gracias a la labor realizada por diversos autores ya en la segunda mitad del siglo XX. Además de las aportaciones de la propia Ángela Franco Mata o José Manuel Gómez Tabanera entre otros, sin duda especial mención merece, en nuestra opinión, el trabajo etnográfico de Valentín Monte Carreño, que ya en los años 80 del siglo XX recogió un importante legado material e inmaterial, hoy por hoy prácticamente desaparecido, en torno al uso de herramientas tradicionales, las formas de trabajo y la historia de la explotación minera y los mineros y artesanos de Les Mariñes (Villaviciosa), en buena medida gracias a los testimonios orales de algunos de los propios protagonistas hoy desaparecidos. Sin este trabajo pionero, a día de hoy habríamos perdido la mayor parte de ese legado (Monte, 1986; Monte, 2004)

No tenemos datos que nos permitan afirmar cuando comienza la explotación minera propiamente dicha de esta materia prima en la península ibérica. Se ha encontrado material en bruto junto a piezas elaboradas en varios yacimientos, pero entendemos que la explotación de la materia prima se haría posiblemente mediante la recolección de material en afloramientos en superficie, o en las playas y argayos de los acantilados, tal y como lo hacen hoy en día algunos artesanos, no teniendo, hoy por hoy, evidencias arqueológicas de una explotación minera como tal anterior a la relacionada ya con el Camino de Santiago y fechas posteriores (Fig. 2). En el caso asturiano, por el momento, la noticia documental más antigua sobre una concesión minera relativa a esta materia prima data de la primera mitad del siglo XV en Oviedo. Los trabajos mineros en la zona rural de Les Mariñes (Villaviciosa), principal foco productor, están bien documentados en época moderna y contemporánea. Estas labores no estaban profesionalizadas y eran realizadas por los propios campesinos de forma estacional. El material se extraía mediante la realización de galerías angostas, a modo de gateras, con métodos manuales y herramientas muy rudimentarias (Fig. 2). Solo hubo un intento de modernización, con la introducción de nuevos métodos de trabajo en los primeros años del siglo XX, de mano de la alta demanda de la moda victoriana, y ya poco antes del cierre definitivo de las minas (Monte, 1986).

En el caso inglés, el otro centro productor por excelencia de Europa Occidental, el material se recogería, como en el caso asturiano, en afloramientos, playas o acantilados hasta el inicio de la minería, que daría inicio allí, según diversos autores, a mediados del siglo XIX (Allason-Jones, 1996; Muller, 1987).
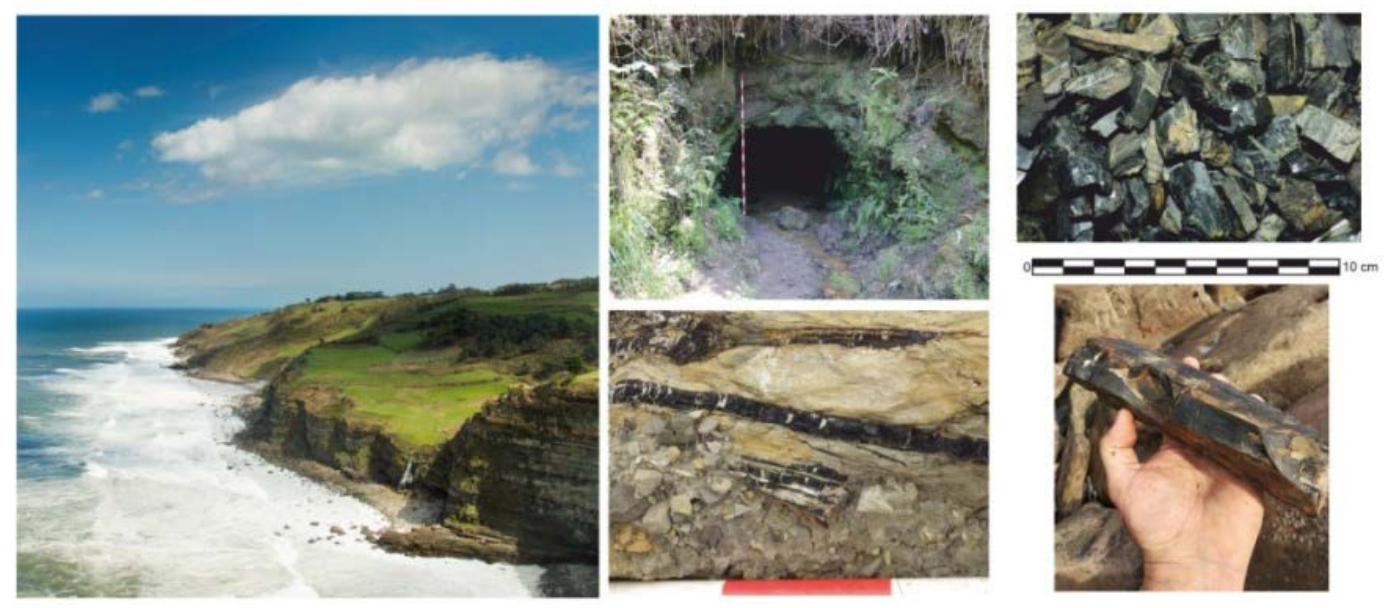

Fuente: Menéndez, A. y Ordieres, B.

Fig. 2 Izquierda, acantilados y entorno minero de Oles (Les Mariñes, Villaviciosa, Asturias). Arriba bocamina de azabache abandonada y restos de material de escombrera en Oles. Abajo izquierda, veta de azache en acantilado en Oles. Abajo derecha, muestra de azabache recogida en argayo en Oles 
Tanto en el caso inglés, como en el español, todas las minas de azabache cerraron oficialmente entre finales del siglo XIX y las dos primeras décadas del XX. Un siglo en el cual el abastecimiento de los artesanos que han seguido trabajando con material local, ha sido, como antaño, los argayos de los acantilados, excavaciones ilegales, proveedores ilegales sin ningún tipo de garantía y las escombreras centenarias de desecho ubicadas en las bocaminas de la zona mariñana, testigo de esplendores pasados, de las que ya se afirmaba que estaban prácticamente agotadas en los años 70 y 80 (Fig. 2). Una labor muy importante fue también la de figuras emblemáticas como el denominado "último minero", Tomás Noval, que tras el cierre de las minas, ya desde adolescente, siguiendo los pasos de su padre y de su abuelo, abasteció a muchos artesanos asturianos y gallegos trabajando en una mina y escombrera propiedad de su familia, prácticamente hasta su fallecimiento, con 87 años, en el año 2008.

Para el estudio actual del legado minero, ya desaparecido en buena parte de los antiguos históricos centros productores, es de especial interés analizar otros puntos geográficos donde esta industria minera se mantiene todavía viva, aunque en retroceso. Es el caso por ejemplo de Turquía, donde las angostas galerías de las minas de la zona rural de Erzurum son todavía parcialmente explotadas de manera tradicional, con herramientas rudimentarias y también con carácter estacional, como sucedía en el caso asturiano, pudiendo establecer interesantes paralelismos y estudios comparativos de carácter etnográfico (Kalkan et al., 2012; Kinaci, 2013; Parlak, 2001) (Fig. 3). Sin embargo se trata también de una industria en decadencia en la actualidad ya que, al igual que en otros centros productores ya citados, desde hace años se importa materia prima de Georgia, que es también denominada en Turquía "piedra rusa" y considerada de segunda calidad, que es más fácil de obtener, poniendo en crisis la industria minera extractiva local y su continuidad (Kokaman, 2013). Sin embargo, Georgia también guarda un importante legado histórico y arqueológico en torno a la explotación de estas materias primas (Menéndez, 2019b).
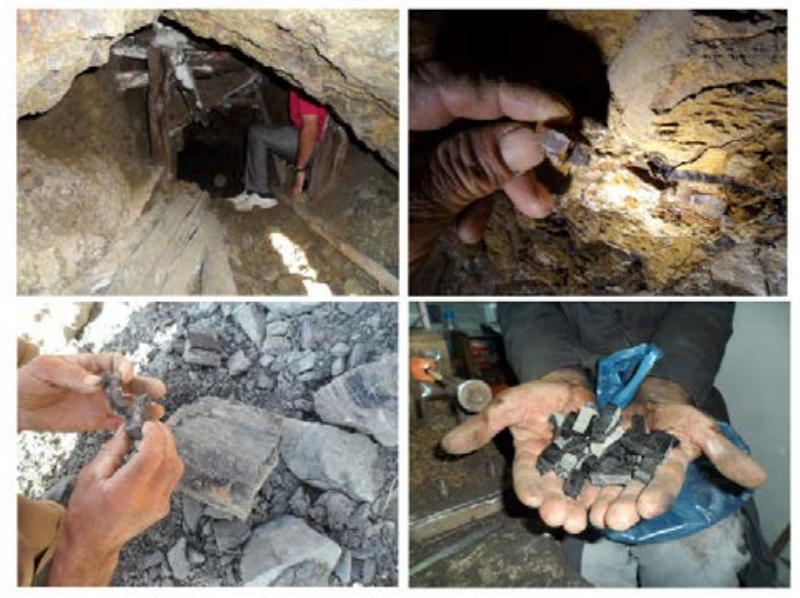

Fuente: Kinaci, E.H.

Fig. 3 Zona minera de Erzurum (Turquía) y artesano mostrando fragmentos de material en bruto

Procesos similares podemos rastrearlos en diversas zonas del mundo, en la mayoría de los casos ya totalmente extinguidos o escasamente estudiados. Otro caso de especial interés para nosotros, por la vinculación cultural con la península ibérica, y que también ha sido parcialmente analizado, es el del denominado azabache venezolano, aunque en este caso, con otras singularidades ya que la materia prima es extraída de las profundidades del río Orinoco con procesos arriesgados y rudimentarios, mediante buceo, que están actualmente también en importante retroceso (Ayala $e t$ al., 2010; González, 1989).

La talla del mineral se ha realizado con herramientas rudimentarias hasta tiempos relativamente recientes y similares en diversos centros productores ya citados (Fig. 5). Hoy en día se han incorporado herramientas mecánicas que cada artesano adapta según sus necesidades, pero hasta hace relativamente poco, en algunos centros, las técnicas no diferían demasiado de las usadas en el pasado, con herramientas sencillas, como cuchillos o navajas, a las que se unían otras que pueden ser rastreadas arqueológicamente en épocas diversas, como el taladro y torno de arco o el parahuso vertical (Fig. 5:1) (Menéndez, 2019b, p. 135 y siguientes). En Asturias, por ejemplo, era un trabajo individual o familiar, donde los 
secretos del oficio se transmitían de forma oral de padres a hijos, o aprendices, y hasta fechas relativamente recientes se utilizaba un banco al que se adaptaba un taladro de arco rudimentario, para la ejecución de perforaciones y pulidos, similar a las herramientas que se utilizaban en el pasado (Fig. 5:3). La mujer, entre otras actividades del oficio, solía realizar el bucido, que era dar forma a la pieza frotando con una piedra de grano húmeda para cerrar los poros, uno de los trabajos más duros del proceso. A mediados del siglo XX se introdujeron ya algunos tornos mecánicos (Monte, 1986).
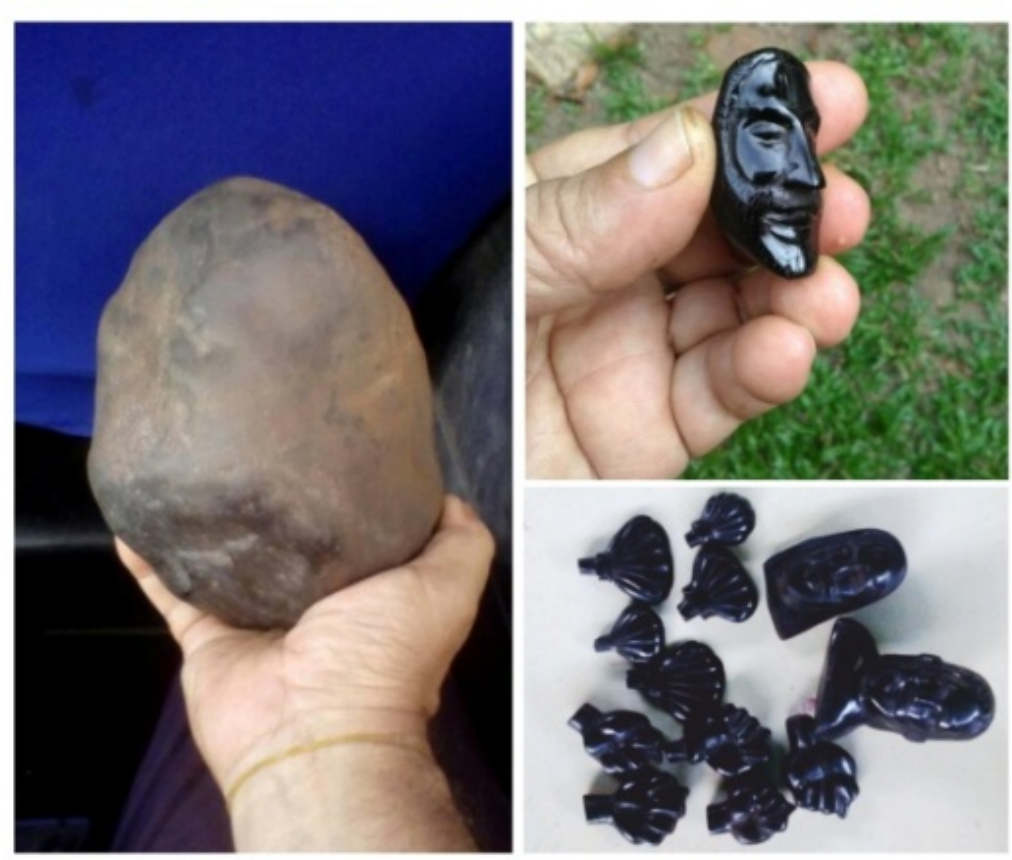

Fuente: Torres, T

Fig. 4 Izquierda, azabache venezolano y a la derecha piezas elaboradas

Turquía también ha sido objeto de estudios en esta línea. El trabajo se realizaba de forma individual y se utilizaban tornos o taladros de arco o manivela, hoy sustituidos por herramientas mecánicas en algunas partes del proceso (Parlak, 2001) (Fig. 5:4). Este tipo de tornos, taladros o parahúsos han sido utilizados desde la prehistoria y en épocas posteriores, siendo múltiples las referencias gráficas que podemos rastrear en este sentido en diversos contextos geográficos, como es el caso de "El libro de los juegos" de Alfonso X, del siglo XIII, donde podemos apreciar el uso de un parahuso, o un torno usado en el suelo, característico de países de Oriente Medio y Próximo entre otros, o norte de África, que se ha mantenido en uso en la actualidad, en el trabajo de diversas materias primas como la madera o el hueso, en lugares como por ejemplo Marruecos, y con similitudes a las técnicas usadas antiguamente en Turquía (Fig. 5:5). El uso de herramientas similares puede también apreciarse claramente en los dibujos de la Casa Mendel y Landauer conservados en la Biblioteca de Nuremberg, considerada la serie más completa y valiosa de artesanía histórica en Europa, que recoge ilustraciones de monjes alemanes realizando diversos oficios, entre el siglo XV y el XVIII, entre ellos varios realizando rosarios de madera (Fig. 5:2) (Menéndez, 2003b, p. 74; Menéndez, 2019b, p. 135 y siguientes).

En el caso venezolano, y otros centros productores como Estados Unidos, el procesamiento posterior del material era similar en el pasado, ligado fundamentalmente al uso de este tipo de herramientas rudimentarias ya citadas, hoy sustituidas por otras más modernas (Ayala et al., 2010; González, 1989; Muller, 1987).

En el caso inglés, ya en el siglo XIX existían grandes talleres ligados a la alta demanda de la moda victoriana, que utilizaban sistemas más sofisticados y parcialmente mecanizados, donde se agrupaban varios trabajadores para realizar diversas tareas en cadena; pero también existían talleres individuales más modestos (Muller, 1987).

En otros casos, como en Georgia, ya se realizaron estudios de tipo etnográfico a finales de los años 50, aunque los artesanos eran recelosos de revelar sus secretos (Petrov, 1982). 


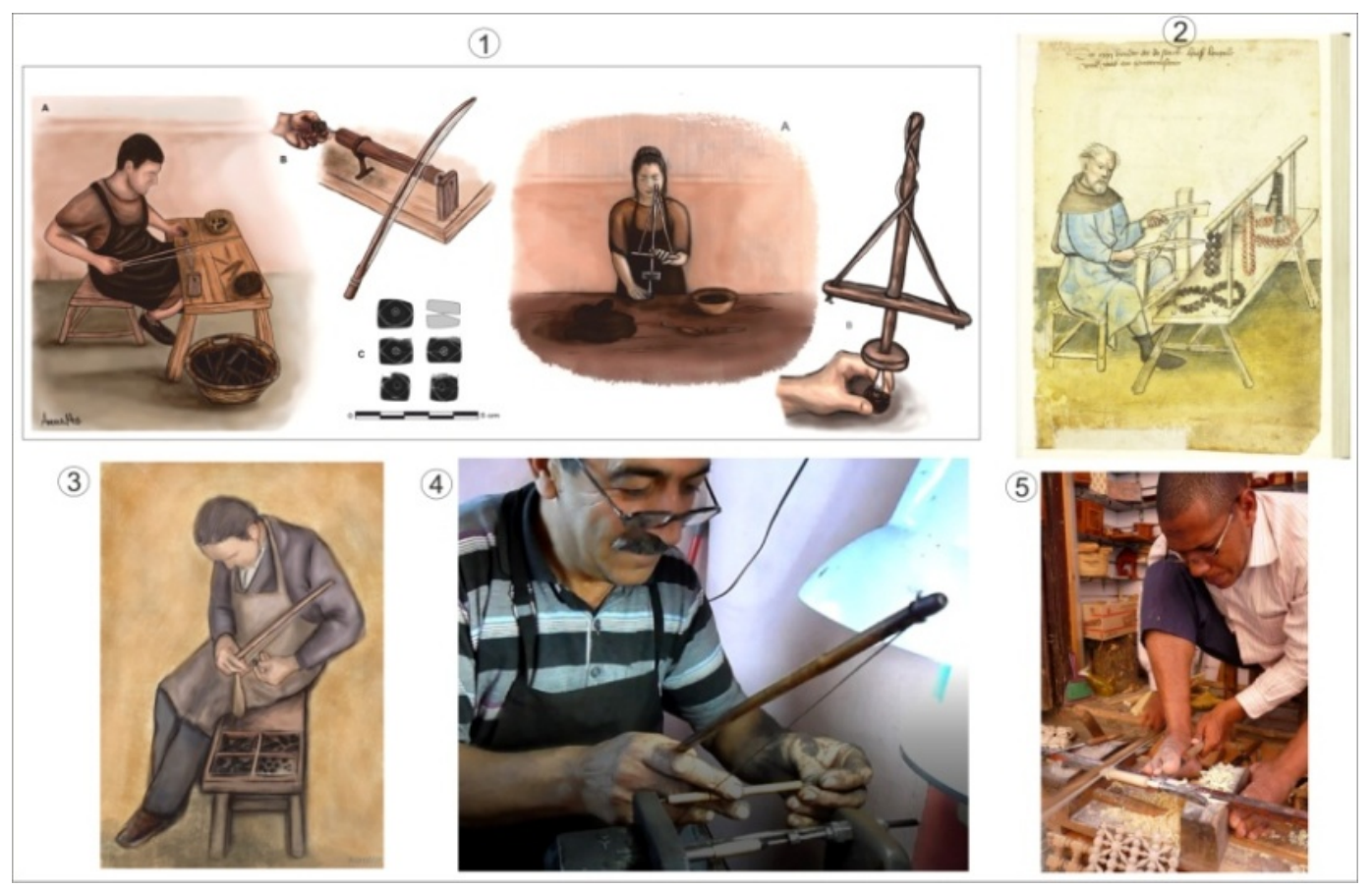

Fuente: 5.1. y 5.3. Menéndez, A.;5.2. Stadtbibliothek Nürnberg/Germanisches Nationalmuseum; 5.4. Kinaci, E.H.; 5.5. Tasbih, N

Fig. 5 1). Recreación de uso del taladro de arco, torno y parahuso, para perforación y decoración en época tardoantigua. 2 ). Monje artesano alemán utilizando taladro de arco para talla de cuentas de madera en el siglo XV. 3). Recreación del uso del banco de azabachero tradicional asturiano con taladro de arco. 4). Maestro artesano turco İsrafil Gümü mostrando el uso de un taladro o torno de arco. 5). Artesano marroquí usando un torno de arco con los pies

\section{La situación actual}

En Europa occidental, los dos principales centros productores hoy en día son Whitby (York) y Asturias. Sin embargo, cien años después del cierre oficial de sus minas, hoy por hoy, el origen de la materia prima no está regulado ni internamente, mediante figuras gremiales hoy inexistentes, ni externamente desde un punto de vista administrativo, problemática que ya hemos abordado más extensamente en otros trabajos (Menéndez, 2019a; Menéndez, e.p.).

Desde las últimas décadas del siglo $\mathrm{XX}$, el abandono de las técnicas de trabajo tradicional o la introducción de materiales foráneos sin control y el uso de otros recursos de bajo coste con fines fraudulentos, como la mezcla de polímeros con polvo de azabache han ido degradando una riqueza cultural, desde el punto de vista artesano, que no dispone de ningún tipo de protección.

En el caso español buena parte del material ha llegado desde Turquía, Georgia o China entre otros; pero el problema de esta artesanía, ya en decadencia mucho tiempo antes, no reside en realidad en la introducción de estos materiales en el mercado, reside en el uso de forma ilícita, o sin control, de los mismos haciéndolos pasar por materiales autóctonos. Algunos artesanos, especialmente fuera de Asturias, trabajan desde hace años de forma abierta con materiales de centros productores foráneos sin prejuicios, lo que sería el camino deseable ante un problema de abastecimiento centenario, hoy por hoy de difícil solución, al igual que sucede con muchos otros productos de índole diversa (Menéndez, 2019a).

Habitualmente se ha optado por desprestigiar el material de origen foráneo públicamente, mientras a la vez ha sido muy utilizado en los talleres desde hace décadas. Esto no es algo nuevo en torno a esta artesanía, al contrario, es lo habitual. Además de otros casos tempranos ya citados; en época victoriana, el sector inglés importó desde España cientos de toneladas de materia prima. Los artesanos ingleses desmerecían, y algunos aún lo hacen, la calidad del material español, al que también culpaban, en buena medida, del colapso de su industria extractiva local, pero sin embargo el origen de la materia prima de una buena parte sus afamadas piezas victorianas, hoy en día objeto de coleccionismo y vendidas como 
"Whitby Jet" es precisamente España. A la vez que esto sucedía, los españoles despreciaban el proveniente de Francia o Portugal. Cada centro productor ha tendido a considerar su materia prima de mejor calidad que el resto, en discursos vacíos que han demostrado ser improductivos desde hace décadas y que hoy en día se mantienen erróneamente intentado ensalzar lo propio mediante el desprestigio constante de lo ajeno, lo cual resulta llamativo en centros productores sin ningún tipo abastecimiento legal u oficial.

Al contrario de lo que se afirma desde diversos sectores artesanos, el origen geográfico de la materia prima, en ningún caso puede determinar, o garantizar, la calidad de las piezas talladas, puesto que, como ya hemos citado y abordado también en otros trabajos, en los afamados centros productores históricos, como pueden ser España o Inglaterra, también se localiza materia prima de calidad inferior, o materiales afines, que han sido tradicionalmente explotados y tallados, e incluso combinados en un mismo conjunto ornamental en cronologías muy diversas. La calidad u origen de la materia prima depende actualmente y exclusivamente de la honradez tanto de los artesanos, como de los proveedores.

En el caso español ha habido diversos intentos de puesta en valor de la cultura azabachera, pero tradicionalmente este ha sido un gremio receloso, individualista y difícil de cohesionar, que puede ser un rasgo característico de los gremios singulares y pequeños ya que, como hemos citado, algo similar ha sucedido en otros centros productores. Ya en los años 70 y 80 algunos autores achacaban a la actitud individualista o egocéntrica de algunos artesanos, buena parte de la problemática del sector y la situación, más de 40 años después, no ha cambiado demasiado (Monte, 1986, p. 73 y siguientes).

En el año 1999 surgió un esperanzador proyecto asociativo que puso sobre la mesa las principales necesidades del sector y emprendió caminos de enorme interés, que lamentablemente pronto se vieron truncados por diversos obstáculos. El fallecimiento de figuras emblemáticas, o la mala gestión de recursos, por parte de las administraciones competentes, supusieron la cancelación de diversos proyectos esenciales, como la ansiada apertura de una mina, una escuela taller que recuperase los usos tradicionales y un espacio expositivo dedicado a este legado diferencial, todo ello sumado a una falta total de control o protección de la actividad. Toda esta compleja problemática la hemos abordado recientemente en otros trabajos, ya que nosotros mismos apostamos recientemente por establecer una colaboración con una nueva asociación creada en 2017, escindida de la anterior, para la puesta en marcha en 2018, con motivo del Año Europeo de Patrimonio Cultural, de un proyecto didáctico expositivo, sin ánimo de lucro, de puesta en valor de este legado, con una recreación tipológica de piezas arqueológicas, y formas de trabajo en épocas diversas, en base a nuestra línea de investigación, con el fin de dar visibilidad al sector. Lamentablemente nos vimos obligados a cancelar todo de forma casi inmediata, tras su presentación, debido a las malas prácticas de esta entidad y al uso indebido, y sin autorización, de nuestro trabajo (Menéndez, 2019; Menéndez, e.p.). Sin duda, un síntoma más de la mala salud actual de este legado artesano. Aun así, como nota positiva, todavía existen nuevas incorporaciones en los últimos años que, a pesar de las dificultades, se han interesado por esta materia prima, como es el caso de la artesana asturiana Carmen Valdés, que tras pasar por la directiva de las dos asociaciones existentes, trabaja hoy en día, como otros artesanos, de forma independiente, con material autóctono recogido por ella misma en los argayos de los acantilados creando joyas con un estilo propio (Fig. 6, abajo)

En el caso inglés, con similar situación, sí han sabido, sin embargo, sacar rentabilidad a su legado histórico con tiendas centenarias y espacios expositivos públicos y privados, con lugares tan interesantes, entre otros, como un antiguo taller victoriano aparecido intacto en un ático durante unas obras, que es hoy en día visitable en una de las tiendas de la ciudad "The Whitby Jet Heritage Centre”, propiedad del reconocido azabachero Hal Redvers-Jones.

En el caso turco ha habido también diversas iniciativas tanto gubernamentales, como no gubernamentales, que surgieron ya en los años 80 para la puesta en valor, y protección, de esta artesanía y un interés por su estudio y mantenimiento. En el palacio del siglo XVI, conocido como Taşhan, en Erzurum, es donde, desde entonces, se agrupan buena parte de los puestos de producción y venta de la artesanía ligada a esta materia prima, que está muy viva. Producen materiales del gusto popular como boquillas, pipas, joyas diversas y fundamentalmente los afamados tasbih o masbaha, piezas para el rezo similares a los rosarios, muy apreciados en todo el país, que tienen una amplia clientela y son vendidos tanto en el entorno de Erzurum, como principalmente en el Gran Bazar de Estambul (Parlak, 2001; Parlak, 2018). 
En Venezuela también se han realizado diversos estudios en las últimas décadas en la misma línea, pero la situación actual del país también supone un importante hándicap para su mantenimiento.
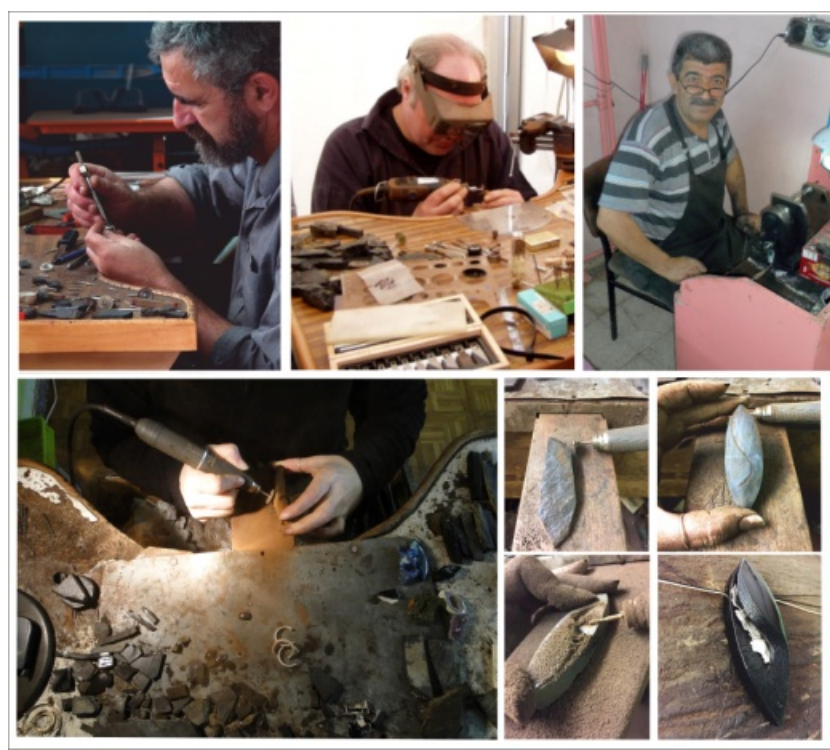

Fuentes arriba: Lafuente, L.; Menéndez A.; Kinaci, E.H.; Torres. T. Fuentes abajo:Menéndez, A. Valdés, C

Fig. 6 Arriba, de izquierda a derecha, el emblemático artesano asturiano Eliseo Nicolás "Lise" en su taller, tristemente fallecido en 2012. Artesano inglés, Hal Redvers-Jones, referente del trabajo en azache en Whitby. Artesano İsrafil Gümü de Turquía en su taller. Tito Torres Loreto, artista venezolano. Abajo izquierda artesana asturiana Carmen Valdés en su taller. Derecha, dos piezas en fase de elaboración y ya terminadas de esta artesana

\section{Conclusiones}

Como hemos visto de forma sucinta a lo largo de estas páginas, la industria y la cultura azabachera comparten rasgos comunes en diferentes partes del mundo en cuanto a su explotación, talla y simbolismo. Algunas de estas conexiones, dentro del mundo de las mentalidades pueden ser rastreadas desde la prehistoria hasta la actualidad, en cuanto a un uso protector centrado en de la propia materia prima, con connotaciones propias, que en ocasiones se han unido a una forma o decoración determinada, con el fin de acrecentar su supuesto poder mágico-defensivo. El uso de un mismo material compartiendo iconografías, formas, patrones decorativos y similar simbolismo en puntos muy dispares del planeta, incrementa su valor como patrimonio, tanto material, como inmaterial.

Desde nuestro punto de vista, el interés de este legado reside, no solo en la singularidad propia de cada territorio, donde se convierten en patrimonios diferenciales, sino en las históricas conexiones culturales que comparten en cuanto a su forma de explotación, su talla y su uso.

En el caso asturiano, con decenas de espacios expositivos ligados a otras temáticas, en su mayoría no tan diferenciales como es la industria y cultura azabachera, no existe ningún tipo de propuesta cultural, o expositiva, ligada a esta riqueza patrimonial. En el principal foco productor de materia prima, como es el caso de Les Mariñes, asentado en un espacio $\mathrm{n}$ rural privilegiado, muy vinculado al mar, con otras importantes riquezas patrimoniales y naturales, su rico legado minero y artesano languidece bajo escombros y derrumbes relegados al olvido, excepto por alguna propuesta privada ligada al turismo activo que surgió en el año 2015, en el entorno minero de Oles (Menéndez y Tuero, e.p).

Tan solo en Galicia, como principal foco artesano ligado al arte compostelano, existen desde hace años diversas propuestas expositivas vinculadas al Camino de Santiago, así como otras colecciones públicas o privadas de interés distribuidas por el resto del territorio peninsular. 
En nuestra opinión, en el caso peninsular, antes de la pérdida irreparable de un legado en buena medida inmaterial, basado en un conocimiento que ha pasado tradicionalmente de padres a hijos relativo a la explotación y procesado de este material; y unas connotaciones que han permanecido en el imaginario colectivo incluso en lugares muy alejados de los centros productores, sería imprescindible la creación de un espacio expositivo público, con sede en el foco minero mariñano por excelencia, pudiendo establecer interesantes relaciones y conexiones, con otros centros productores con similar trayectoria histórica, antes de su pérdida total.

Tras el fracaso constante en Asturias de proyectos enfocados al sector artesano, que actualmente está más ligado a joyeros que trabajan con azabache; mayoritariamente enfocados en otros intereses, con problemáticas más complejas y en buena medida totalmente ajenos a la verdadera tradición y cultura azabachera en sí; sin restar importancia a este punto, en nuestra opinión sería más interesante y primordial centrar el esfuerzo inmediato y los recursos en abordar la cuestión desde una perspectiva puramente patrimonial y expositiva, con una importante vocación didáctica, con la recuperación y catalogación de espacios, herramientas, documentos, piezas, usos y costumbres, que ponga en valor el legado histórico que aún permanece en la memoria colectiva de los descendientes de sus protagonistas, con historias, tradiciones y creencias que son, en buena medida, compartidas en lugares diversos y que trascienden más allá de los propios centros productores.

\section{Referencias}

Allason-Jones, L. (1996). Roman Jet in Yorkshire Museum. Yorkshire: The Yorkshire Museum.

Álvarez-Fernández, E. (1999). Las perlas de madera fósil del terciario y los objetos de adorno-colgantes sobre los dientes de zorro y ciervo del magdaleniense de Gönnesdorf y de Andernarch-Martinsberg-2, (Neuwied, Rheinland Pfalz, Alemania). Zephyrus, (52), 79-106.

Álvarez-Fernández, E. (2003). Azabache et alii: la utilización del lignito durante el Paleolítico Superior en Europa. En E. Allué., J. Martín., A. Canals y Carbonell, E. (Eds.), Actas del ler congreso Peninsular de Estudiantes de Prehistoria (pp. 386-393). Tarragona: Universitat Rovira i Virgili, Area de Prehistoria.

Ayala, T., Malavé, M., Rodríguez, S., Herrero, J., y Paulo, A. (2010). Exploración, evaluación geológica, económica, socioambiental y procesamiento del mineral azabache localizado en el río Orinoco, sectores Vuelta El Torno- El Merey, municipio Sucre, y Caicara del Orinoco-Puerto El Burro, municipio Cedeño del Edo. Bolívar. Geominas, 38(51), 40-45.

Corchón, M. S. (2007-2008). Reflexiones sobre la expresión Artística y las relaciones culturales en el magdaleniense medio cantábrico. A propósito de dos plaquitas grabadas inéditas de Las caldas (Asturias, España). Veleia, (24-25), 175-207.

Costa, A. (2008). Estudo petrográfico e geoquímico das ocorrências de azeviche da região da Batalha-Portugal. Porto: Faculdade de Ciencias da Universida do Porto (Dissertação de Mestrado em Geomateriais e Recursos Geológicos), Departamento de geociências da Universida de Aveiro. Inédito.

Franco, Á. (1986). Azabaches del M.A.N. Boletín del Museo Arqueológico Nacional (Madrid), Tomo IV(2), 131-167.

Franco, Á. (1991). Valores artísticos y simbólicos del azabache en España y el Nuevo Mundo. Compostellanum: revista de la archidiócesis de Santiago de Compostela, 3(3-4), 467-531.

González, L. (1989). Artesanía en azabache, Caracas: Consejo Nacional de la Cultura.

Hagen, W. (1937). Kaiserzeitliche gagatarbeiten aus dem rheinischen Germanien. Bonner Jahrbücher, Heft (142), 77-144.

Hernández-Vaquero, M. C. (2015). La evolución del arte del azabache en España y el Reino Unido. (Tesis doctoral inédita). Madrid: Universidad Autónoma de Madrid

Kalkan, E., Bilici, Ö., y Kolayli, H. (2012). Evaluation of Turkish black amber: A case study of Oltu (Erzurum), NE Turkey. International Journal of Physical Sciences, 7(15), 2387-2397.

Kinaci, E. H. (2013). Mineralogical and gemological investigation and genesis of oltu stone (carbon black), (Tesis inédita). Dokuz Eylül University.

Kocaman, S. (2013). Russian Stone as a Touristic Product (Georgian Black Amber) and Its Effects to Erzurum Oltu Stone Sector. Eastern Geographical Review, 18(30), 115-134. 
Aproximación al pasado, presente y futuro de la industria azabachera, un patrimonio cultural, material e inmaterial, en vías de extinción

Martínez, S. (2016). Producción y consumo de piedras semipreciosas al final de la Edad Media : el azabache de Montalbán (Aragón) en el siglo XV. En Laliena, C. y Lafuente, M. (coord.). Consumo, comercio y transformaciones culturales en la baja Edad Media: Aragón, siglos XIV y XV (pp.47-68). Zaragoza : Universidad de Zaragoza.

Menéndez, A. (2003a). Azabache. En Gutiérrez, J. A. (2003). Peñaferruz (Gijón). El Castillo de Curiel y su territorio, (pp. 269-278). Gijón: VTP Editorial.

Menéndez, A. (2003b). La Industria del azabache en la Asturias Medieval. (Tesina Inédita). Oviedo: Universidad de Oviedo.

Menéndez, A. (2019a). Patrimonios culturales en peligro de extinción. La cultura azabachera. En Álvarez, E. y Iglesia. M.A. Actas Congreso Internacional XI Bienal Ibérica del Patrimonio Cultural. El papel del Patrimonio en la construcción de la Europa de los ciudadanos 2018 (pp. 519-528).Valladolid: LAB/PAP Laboratorio de Paisaje Arquitectónico, Patrimonial y Cultural y Departamento de Teoría de la Arquitectura y Proyectos Arquitectónicos, Universidad de Valladolid,

Menéndez, A. (2019b). Aproximación histórica y tipológica al uso del azabache, y otros materiales afines, durante la época romana y la Tardoantigüedad en la península ibérica, Nailos. Estudios Interdisciplinares de Arqueología (6), 123-203.

Menéndez, A. (e.p.). Azabache, agua y piedra. Patrimonio y turismo sostenible. Antecedentes y posibilidades en el entorno rural de Les Mariñes (Villaviciosa, Asturias). XXI Jornadas Internacionales de Patrimonio Industrial 2019. Gijón: INCUNA Industria, Cultura y Naturaleza.

Menéndez, A. y Tuero, J. (e.p.). Turismo Activo y Patrimonio Cultural. Sinergias para el impulso del mundo rural en Les Mariñes (Villaviciosa, Asturias, España). Congreso Internacional de Socialización del Patrimonio en el Mundo Rural, Colombia 2019.

Monte, V. (1986). Azabachería asturiana, Consejería de Educación. Oviedo : Cultura y Deportes del Principado de Asturias.

Monte, V. (2004). El azabache. Piedra mágica, joya, y emblema jacobeo. Llanera, Asturias: Editorial Urriellu.

Muller, H. (1987). Jet. Great Britain: Butterworths Gem Books.

Ona, J. L. (1998). Noticia de la extracción y elaboración del azabache en la villa y tierra de Montalbán. Artigrama 13: pp. 427-435.

Osma, G. de (ed.1999). Catálogo de azabaches compostelanos. Santiago de Compostela: Ara Solis. Edición facsimilar.

Parlak, T. (2001). Erzurum'da oltu taşi ve kuyumculuk sanat. Oltu: Oltu: Ticaret ve Sanayi Odası Kültür Yayınları.

Parlak, Y. (2018). Oltu taşi ve oltu'da bir tespih ustasi: Israfil Gümüş. Ulakbilge, 6(21), 179-191.

Petrov, V.P. (1982). Rasskazy o podeločnom kamne. Moskva: Nauka.

Suárez, I.; Iglesias, M.J.; Jiménez, A.; Cuesta, M.J. y Laggoun-défarge, F. (2006). El azabache de Asturias: características físicoquímicas, propiedades y génesis. Trabajos de Geología 26, 9-18.

Travaços, J. (2011). Os Azevicheiros da Batalha, Jornal da Batalha, 253(22), 20. https://issuu.com/jornal_da_batalha/docs/binder_edicao_253_agosto_2011 